\title{
Evaluating Reverse Supply Chain Efficiency: Manufacturer's Perspective
}

\author{
Manasvi Kumar, ${ }^{1}$ Manoj Kumar Tiwari, ${ }^{2}$ Kuan Yew Wong, \\ Kannan Govindan, ${ }^{4}$ and Chuen Tse Kuah ${ }^{3}$ \\ ${ }^{1}$ Department of Ocean Engineering and Naval Architecture, Indian Institute of Technology, Kharagpur 721302, India \\ ${ }^{2}$ Department of Industrial and Systems Engineering, Indian Institute of Technology, Kharagpur 721302, India \\ ${ }^{3}$ Department of Manufacturing and Industrial Engineering, Faculty of Mechanical Engineering, Universiti Teknologi Malaysia, \\ 81310 Skudai, Malaysia \\ ${ }^{4}$ Department of Business and Economics, University of Southern Denmark, 5230 Odense, Denmark
}

Correspondence should be addressed to Kuan Yew Wong; wongky@fkm.utm.my

Received 20 May 2014; Accepted 22 June 2014; Published 10 July 2014

Academic Editor: Tsan-Ming Choi

Copyright (C) 2014 Manasvi Kumar et al. This is an open access article distributed under the Creative Commons Attribution License, which permits unrestricted use, distribution, and reproduction in any medium, provided the original work is properly cited.

\begin{abstract}
The paper aims to illustrate the use of fuzzy data envelopment analysis (DEA) in analyzing reverse supply chain (RSC) performance from the manufacturer's perspective. By using an alternative $\alpha$-cut approach, the fuzzy DEA model was converted into a crisp linear programming problem, thereby altering the problem to an interval programming one. The model is able to obtain precise and robust efficiency values. An investigation was also made between the obtained efficiency scores and certain relevant background information of the companies. The study revealed that while ISO 14001 certification usually ensures an environmentally friendly supply chain network, companies which have implemented RSC techniques since a longer duration do not necessarily have a more efficient supply chain in general.
\end{abstract}

\section{Introduction}

Individual companies are no longer in a position to compete as distinct self-sufficient entities, thus forcing them to focus their attention towards supply chains. In the current competitive environment, the ability of a business to succeed will depend on the ability of the manufacturer to integrate itself into the intricate network of the supply chain. It is noted that a supply chain is not a chain of companies with one-to-one, business-to-business relationships but a network of multiple companies and relationships. The operations in supply chains and logistics are part of today's most significant commercial activities as they are pivotal for businesses to remain viable. The two main goals of managing a supply chain are to realize where a particular company stands among its competitors and how it can be developed further.

To understand how proficiently a company is performing in a supply chain, we measure its efficiency. Traditionally, the efficiency of a supply chain was measured by taking the ratio of revenue over the total supply chain operational cost. Nonetheless, there are several additional objectives of a business apart from monetary benefits. These objectives depend on several factors, namely, societal factors, environmental factors, technological factors, and so forth. Incorporating all these multiple factors in the form of inputs and outputs to determine efficiency is difficult without the right tool. Therefore, finding the efficiency while incorporating multiple inputs and outputs for a reverse supply chain (RSC) is even more challenging, as this is not something traditionally done.

The aim of RSC is to help in collecting, recycling, reusing, or disposing end-of-life products. It is crucial to recapture the value of products and to provide methods for proper disposal [1]. The process is usually very complex, with many individual players involved in it (such as customers, collectors, recyclers, etc.). Progress in RSC is slow as it is not usually considered as a system which could return sufficient value for the resources involved. Thus, it becomes very important to efficiently 
manage this chain. Efficiency measurement of RSC remains to be a relatively underdeveloped and unexplored area [2]. Instead of focusing on the entire RSC, this paper intends to measure the efficiency of RSC from a manufacturer's perspective. Thus, only data obtained from manufacturers have been considered.

The main contribution of this study is to pioneer the evaluation of RSC efficiency by primarily using data envelopment analysis (DEA). DEA was first proposed by Charnes et al. [3] and is a nonparametric method of efficiency analysis for associating units relative to their best peers (efficient frontier). Mathematically, it is a linear programming-based methodology for evaluating the relative efficiencies of a set of decision making units (DMUs). DEA accepts multiple inputs and outputs, making it ideal for estimating the efficiency of a complex structure like the supply chain which involves many attributes. However, one major point of concern is that observed values of the input and output data in real-world RSC scenarios are often not precise. Imprecise evaluation may be the result of incomplete and unavailable information. Therefore, various fuzzy methods for dealing with this impreciseness in DEA have been proposed. In this paper, a fuzzy version of the CCR model (please refer to Section 3) is utilized to obtain the RSC efficiencies of different companies from a manufacturer's point of view. Other background information of the respective companies has been collected. A comparison of this data has given greater insights into the reason why certain companies have not performed well in implementing an efficient RSC system.

In general, the paper is structured as follows. Section 2 reviews the efficiency measurement for RSC. Section 3 deals with the explanation of the fuzzy DEA model used to measure RSC efficiency. In Section 4, the overall model is presented, carefully explaining the reasons behind selecting its performance attributes. Next, Section 5 explains the data collection process. Following this, Section 6 presents and discusses the results obtained from a real-world application of the model. Finally, in Section 7, conclusions are drawn from the paper and future research directions are highlighted.

\section{Literature Review}

Prahinski and Kocabasoglu [4] defined RSC as the effective and efficient management of the series of activities required to retrieve a product from a customer and either dispose it or recover its value. The importance of understanding RSC has increased due to several reasons. As mentioned by Trebilcock [5], the amount of product returns has risen over $50 \%$ of sales for many industries. End-of-life take-back laws and environmental conscious consumers have pressured companies to take responsibility for the disposal of their products which could contain hazardous substances. Additionally, landfill capacity has become more and more limited and expensive, and thus recycling end-of-life products has become more viable [6]. Despite its importance, RSC is usually not a firm's core business because getting top managers' attention and measuring its performance are a difficult task [7].
For measuring the efficiency of a supply chain, it is essential to obtain the input and output data values. In the case of the forward supply chain, the data required are usually available as they have traditionally been used by companies to keep track of their goods or services. These data are critical as most businesses make use of them as a measure of growth and market share. Thus, measuring the efficiencies of forward supply chains can be done by normal DEA or other methods as the data are normally available.

Now consider the case of RSC. The importance of RSC has not reached the maturity level of forward supply chain. Recycling or reusing of goods is not as common as production of goods. So it is difficult to find companies which have recycled for more than 10 years, even though they could have existed for thrice as long. Even in the case that recycling is a very important aspect in an industry (say paper industry), the informatics involved in RSC is not as high as that of forward supply chain. In addition, for some cases like measuring the impact of business activities on the environment, it may not be possible to obtain all required data with the required preciseness [8].

A literature review related to the performance measurement of RSC has been performed by Taticchi et al. [9] and they called for a more structured approach to evaluate its performance. In addition, there are limited existing performance measurement tools which have been applied in RSC and they may not be adequate to fully assess its efficiency. Some tools which have been utilized in applications related to RSC performance evaluation are, for example, analytical hierarchy process $[10,11]$, life cycle assessment [12], activitybased costing [13], balanced scorecard [14], and fuzzy logic [15].

There are very few papers published in which RSC performance has been evaluated directly. It is observed that the measurement of RSC efficiency by nonfuzzy methods is difficult due to the lack of precise numerical data required. Another observation on previous studies is the analyses were done on a single supply chain instead of multiple supply chains. Therefore, there is a need for a more robust tool to handle the unavailability of precise data and to benchmark multiple supply chains. One tested method in case of unavailability of data is the use of linguistic data. So in this condition, data are measured by qualitative values which have ordinal relations. For example, words like "Excellent," "Good", and "Average" could be used to describe certain attributes, and from this we can conclude that "Excellent" is better than "Good" which is in turn better than "Average."

It is also observed that fuzzy DEA has been developed over the past few years and has been proven to successfully measure efficiencies [16-21]. One of the biggest advantages of using fuzzy DEA to solve RSC models is the use of linguistic data to achieve precise and robust efficiency values. Thus, in this paper, a fuzzy version of the CCR model has been applied to analyze RSC performance. This has also allowed the researchers to obtain data from more companies as the information requested is basically linguistic. In addition, different types of companies can be approached, which could differ by the type of product, the monetary scale, and other factors. 


\section{Mathematical Model}

This paper utilizes DEA as the base model for RSC evaluation. The first DEA model is called CCR model which was developed by Charnes et al. [3]. DEA is a mathematical model used to measure the relative efficiencies of a group of homogenous organizations (commonly referred to as decision making units or DMUs in the DEA literature) that convert multiple inputs into multiple outputs. It is favorable for performing benchmarking analysis because it does not need any prior weight to be assigned to the measures and thus reducing subjective or biased judgment on the results.

Assume that there are $n$ DMUs $\left(\mathrm{DMU}_{1}, \mathrm{DMU}_{2}, \ldots\right.$, $\mathrm{DMU}_{n}$ ) to be evaluated. Varying amounts of $m$ different inputs are consumed by each DMU to produce $s$ different outputs. The $j$ th DMU $\left(\mathrm{DMU}_{j}\right)$ consumes $m$ inputs $x_{i j}(i=$ $1, \ldots, m)$ to produce $s$ outputs $y_{r j}(r=1, \ldots, s)$. In the following model, the crisp vectors of input and output values of the current $\mathrm{DMU}$ under evaluation, $\mathrm{DMU}_{p}$, are represented by $x_{i p}(i=1, \ldots, m)$ and $y_{r p}(r=1, \ldots, s)$, respectively. The CCR model is defined as follows:

$$
\begin{array}{ll}
\text { Max } & W_{p}=\sum_{r=1}^{s}\left(u_{r} y_{r p}\right) \\
\text { s.t. } & \sum_{i=1}^{m}\left(v_{i} x_{i p}\right)=1 \\
& \sum_{r=1}^{s}\left(u_{r} y_{r j}\right)-\sum_{i=1}^{m}\left(v_{i} x_{i j}\right) \leq 0 \quad \forall j \\
& u_{r}, v_{i} \geq 0 \quad \forall i, r .
\end{array}
$$

Model (1) requires precise information and data, which may not be available in all cases, but this does not end the modeling of a complex system. Generally, the lack of quantitative data required to solve model (1) is made up by obtaining qualitative data. As it is not feasible to incorporate qualitative data into this model directly, this model is to be modified. In other words, a fuzzy approach seems ideal for such a complex system. The method proposed by Saati et al. [22] has been implemented to introduce fuzziness into the CCR model. The CCR model with fuzzy data can be written as follows:

$$
\begin{array}{ll}
\operatorname{Max} & W_{p}=\sum_{r=1}^{s}\left(u_{r} \widetilde{y}_{r p}\right) \\
\text { s.t. } & \sum_{i=1}^{m}\left(v_{i} \widetilde{x}_{i p}\right)=\widetilde{1} \quad \forall i \\
& \sum_{r=1}^{s}\left(u_{r} \widetilde{y}_{r j}\right)-\sum_{i=1}^{m}\left(v_{i} \widetilde{x}_{i j}\right) \leq 0 \quad \forall j \\
& u_{r}, v_{i} \geq 0 \quad \forall i, r,
\end{array}
$$

where $\sim$ is used to denote fuzziness.

Triangular fuzzy numbers are extensively used as fuzzy inputs. Thus, the fuzzy input in model (2) is in the form of $\widetilde{x}=$ $\left(x^{m}, x^{l}, x^{u}\right)$ with $x^{l} \leq x^{m} \leq x^{u}$. Similarly, the fuzzy output is in the form of $\tilde{y}=\left(y^{m}, y^{l}, y^{u}\right)$ with $y^{l} \leq y^{m} \leq y^{u}$.
Let $\tilde{x}_{i j}=\left(x_{i j}^{m}, x_{i j}^{l}, x_{i j}^{u}\right)$ and $\tilde{y}_{r j}=\left(y_{r j}^{m}, y_{r j}^{l}, y_{r j}^{u}\right)$. The previous model is updated as follows:

$$
\begin{array}{ll}
\text { Max } & W_{p}=\sum_{r=1}^{s} u_{r}\left(y_{r p}^{m}, y_{r p}^{l}, y_{r p}^{u}\right) \\
\text { s.t. } & \sum_{i=1}^{m} v_{i}\left(x_{i p}^{m}, x_{i p}^{l}, x_{i p}^{u}\right)=\left(1,1^{l}, 1^{u}\right) \quad \forall i \\
& \sum_{r=1}^{s} u_{r}\left(y_{r j}^{m}, y_{r j}^{l}, y_{r j}^{u}\right)-\sum_{i=1}^{m} v_{i}\left(x_{i j}^{m}, x_{i j}^{l}, x_{i j}^{u}\right) \leq 0 \quad \forall j \\
& u_{r}, v_{i} \geq 0 \quad \forall i, r .
\end{array}
$$

Model (3) represents a possibilistic linear programming problem. One widely used method for solving this type of problem is the $\alpha$-cut approach. Thus, incorporating the $\alpha$-cut approach changes the model as follows:

$$
\begin{array}{cl}
\operatorname{Max} & W_{p}=\sum_{r=1}^{s} u_{r}\left[\alpha y_{r p}^{m}+(1-\alpha) y_{r p}^{l}, \alpha y_{r p}^{m}+(1-\alpha) y_{r p}^{u}\right] \\
\text { s.t. } \quad \sum_{i=1}^{m} v_{i}\left[\alpha x_{i p}^{m}+(1-\alpha) x_{i p}^{l}, \alpha x_{i p}^{m}+(1-\alpha) x_{i p}^{u}\right] & \\
= & {\left[\alpha+(1-\alpha) 1^{l}, \alpha+(1-\alpha) 1^{u}\right] \quad \forall i,} \\
\sum_{r=1}^{s} u_{r}\left[\alpha y_{r j}^{m}+(1-\alpha) y_{r j}^{l}, \alpha y_{r j}^{m}+(1-\alpha) y_{r j}^{u}\right] \\
-\sum_{i=1}^{m} v_{i}\left[\alpha x_{i j}^{m}+(1-\alpha) x_{i j}^{l}, \alpha x_{i j}^{m}+(1-\alpha) x_{i j}^{u}\right] \\
\leq 0 \quad \forall j \\
u_{r}, v_{i} \geq 0 \quad \forall i, r .
\end{array}
$$

Model (4) can be solved in an efficient and robust manner by incorporating variables in the intervals which are capable of satisfying the set of constraints and maximizing the objective function at the same time. Thus, the final model is transformed to:

$$
\begin{array}{ll}
\operatorname{Max} & W_{p}=\sum_{r=1}^{s}\left(\bar{y}_{r p}\right) \\
\text { s.t. } & \sum_{i=1}^{m}\left(\bar{x}_{i p}\right)=1 \\
& \sum_{r=1}^{s}\left(\bar{y}_{r j}\right)-\sum_{i=1}^{m}\left(\bar{x}_{i j}\right) \leq 0 \quad \forall j, \\
& v_{i}\left(\alpha x_{i j}^{m}+(1-\alpha) x_{i j}^{l}\right) \\
\leq \bar{x}_{i j} \leq v_{i}\left(\alpha x_{i j}^{m}+(1-\alpha) x_{i j}^{u}\right) \quad \forall i, j, \\
u_{r}\left(\alpha y_{r j}^{m}+(1-\alpha) y_{r j}^{l}\right) \\
\leq \bar{y}_{r j} \leq u_{r}\left(\alpha y_{r j}^{m}+(1-\alpha) y_{r j}^{u}\right) \quad \forall r, j, \\
u_{r}, v_{i} \geq 0 \quad \forall i, r .
\end{array}
$$




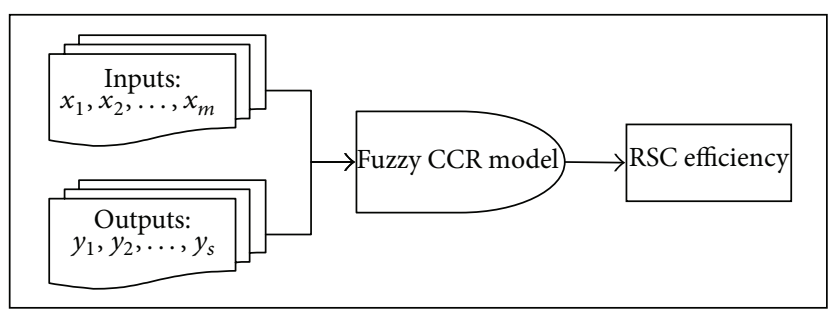

FIgURE 1: Conceptual framework for RSC evaluation.

Model (5) is now a parametric programming model with $\alpha$ being a parameter between 0 and 1 , thereby converting it into a parametric linear programming problem. Now for each $\alpha$ value, there exists an optimum solution. Thus, the efficiency scores may change due to the value of $\alpha$. It is quite noticeable that lower $\alpha$ values help in providing a greater range, thereby helping in better optimization for any particular DMU in general. So one could expect the value of the efficiency score to decrease or remain constant with increasing $\alpha$. This point will be further discussed in Section 6 .

Once the data are entered into the model, it generates the efficiency score of the RSC. As the efficiency has been evaluated from the manufacturer's perspective, it gives an idea of how well the manufacturer has adjusted into the supply chain. Lower efficiency implies that the manufacturer could focus more on recycling or reusing aspects of its business. Higher efficiency implies that the manufacturer has adjusted properly into the supply chain, and hence it is not only performing well individually but also helps in the overall supply chain to be more efficient. The result of this model is twofold. It helps in providing a reliable and robust efficiency score from linguistic data which would otherwise be difficult to calculate because of lacking numerical information. It also helps in effective comparison of companies which are not of similar production type, as the input of linguistic data has ensured a similar comparison ratio as opposed to numerical data.

\section{Overall Model}

Figure 1 shows the conceptual framework for evaluating RSC efficiency. Firstly, the data are collected which represent the input and output values of a particular DMU. The efficiency is calculated from the manufacturer's perspective. Hence, it is of great importance that the inputs and outputs have been formulated such that the manufacturer answers these based on its performance in the field of interest. Following the triple bottom-line framework in sustainability [23] and a critical review on the literature, the developed input and output measures cover the major aspects of a company's RSC, namely, environmental, economic, societal, and operational aspects, investment, and relationship between supply chain parties. These aspects ensure that the study covers diverse elements of RSC, thus making the study more relevant. It is also important to note that most of these performance attributes will not have been documented or measured quantitatively by a manufacturer. Hence, linguistic data are collected from each manufacturer. This proves to be very useful as normally, attributes like societal measures do not have any measuring yardstick. With the use of linguistic data, the attributes have managed to accept many diverse factors into one model, thus making it more realistic. Each of these performance attributes is described below.

\subsection{The Input Variables}

$x_{1}$ : Operational and Technological Cost. This performance attribute is mainly concerned with the cost required in operating the recycling or reusing process. It also includes the cost of acquiring the necessary technology. From the manufacturer's point of view, it shows how much capital has been used to implement RSC, hence making it an input variable [24].

$x_{2}$ : Investment in Environmental Initiatives and Certification. Chien and Shih [25] evaluated environmental performance by considering environmental policies and measures, among other factors. This performance attribute is mainly concerned with the amount of money that the manufacturer has invested to make the RSC more environmentally friendly by rolling out pertinent initiatives and obtaining formal certification such as ISO 14001. This is an input because it is the expenditure that has to be spent in order to have an efficient RSC.

$x_{3}$ : Relationship between RSC Parties. This performance attribute is concerned with the smooth functioning of the RSC as a whole [4]. The stronger the relationship between parties is, the easier it is for the supply chain to function properly. Thus, it is considered as an important performance attribute for the model. It is chosen as an input variable because it is an enabler for an efficient RSC.

\subsection{The Output Variables}

$y_{1}$ : Environmental-Reduction of Impact. It is the performance attribute which measures the RSC "greenness." This mainly shows the supply chain's ability to reduce energy consumption, emission, pollution, and waste disposal as given in Papadopoulos and Giama [26]. From the manufacturer's perspective, the impact on the environment is directly related to the approaches adopted in manufacturing. Thus, it is considered as an output variable, as it depends directly on the manufacturer's actions.

$y_{2}$ : Economic-Cost Saving and Profit Generation. Zhu and Sarkis [27] mentioned that economic performance is the most important factor for companies that wish to implement environmental management practices. It is the most widely used performance attribute to measure the efficiencies of various profit-oriented organizations. It mainly deals with the money saved and profit generated by the manufacturer in implementing RSC techniques. It is considered as an output variable as it shows how well the manufacturer has succeeded in implementing RSC techniques. 
$y_{3}$ : Societal-Quality of Life. This performance attribute mainly concerns the health and wellness of people involved in the supply chain, namely, the customers, recyclers, manufacturers, and so forth, as clearly emphasized by Wan and Chan [28]. Apart from the aforementioned, the society at large is affected by the actions of the company. This attribute is considered as an output variable, mostly because it gives an idea of how well the company has managed to function smoothly without adversely affecting the society at large.

Once the data have been obtained, they are then structured and entered into the model (discussed in Section 3). This model calculates precise and robust efficiency scores based on the parameter $\alpha$. It is able to accept different linguistic data and is also able to give various values of efficiency for different values of $\alpha$, thereby separating the truly efficient RSCs from the rest.

\section{Data Collection}

Testing the model in a real-world environment is important for the study. A survey was designed to collect input and output variables data from different companies. The companies were not pertinent to any particular industry. Apart from the aforementioned data, information like product type, number of employees in the company, duration (number of years) for which RSC practices have been adopted, and environmental certification received by the company was also collected. The purpose of this information was to make more in-depth insights as to how the efficiencies are affected by these factors, thereby improving the value of the study. Normally, supply chain efficiencies measured by DEA are more comparable for similar companies, as it measures the relative performances of DMUs which are similar units. However, the use of fuzzy DEA has crossed this barrier, thereby improving the reach of the study to more diverse types of companies, while keeping the efficiencies comparable. As the survey aimed to provide the manufacturer's perspective on RSC, the data from diverse companies helped in analyzing various supply chains from a single perspective. Data collection was done by mailing.

A questionnaire was developed especially for this purpose (please refer to the Appendix). It was evident at the beginning of the study that exact values of the required data would not be easily accessible or in some cases not available. It also became clear that asking for such data which were not accessible might result in very few responses, thereby reducing the response rate significantly. So questions were accompanied by check boxes with answers like "Very High," "High," "Normal," "Low," and "Very Low." Thus, the answers were completely linguistic. In other words, the data collected were fuzzy.

The questionnaire survey was carried out between July and August 2013. The companies were chosen from the Federation of Malaysian Manufacturers Directory. It was evident that not all companies have a functional RSC. Thus, the authors contacted the companies via telephone to check whether they have a proper RSC in place. A total of 70 companies in the Johor region were contacted. Only 44 of these companies satisfied the criterion. Only then, questionnaires were sent to the Managing Directors or Plant Managers of these companies. It is noted that these companies were not producing similar goods. We received responses from 21 companies, which made the response rate a commendable $47.7 \%$. This is mainly due to the linguistic nature of the data required, without which certainly the responses would be lesser and the study would not have been possible. Of these 21 returned questionnaires, 20 were filled completely to the level required for the study. Hence, 20 responses from different types of companies were used in the study. The number of DMUs satisfies the rules of thumb established by Golany and Roll [29], Bowlin [30], and Dyson et al. [31], about the minimum number of DMUs needed for a DEA analysis.

The answers were then assigned with values such as 10 , $30,50,70$, and 90 . Specifically, 10 corresponds to the answer for "Very Low" and 90 corresponds to "Very High," with 50 being the moderate value. The $\left(x_{i j}^{m}, x_{i j}^{l}, x_{i j}^{u}\right)$ and $\left(y_{r j}^{m}, y_{r j}^{l}, y_{r j}^{u}\right)$ values of every input and output for each DMU have been determined. The maximum range of values was set to be \pm 5 of the original value. The reason for this is that it allows a range which should provide enough variation for the optimum value to exist but at the same time prevent any overlap between any two neighboring values. For instance, there is no chance for any permissible value of $\alpha$ that the values of Very Low and Low are the same. At most, Very Low may reach the value of 15 and Low may reach the value of 25, maintaining a minimum gap of 10 throughout. Clearly, the real value of this range also depends on $\alpha$, as explained in the model in Section 3. As the value of the parameter $\alpha$ is chosen, the efficiency score is obtained. $\alpha=$ 0 corresponds to the maximum range and $\alpha=1$ corresponds to the efficiencies being calculated by mean values of the data without considering left or right spreads.

The data from the responses were put into the fuzzy CCR model and solutions were obtained using a MATLAB program written based on the model. The results are presented in the next section.

\section{Results and Discussion}

Table 1 shows the efficiencies of different DMUs for different $\alpha$ values. An efficiency value of 1 means a DMU is efficient in its RSC, while a score less than 1 indicates a DMU is less efficient. Of the 20 DMUs, 9 are efficient when $\alpha=0$ and $\alpha=$ $0.25,8$ are efficient when $\alpha=0.5,7$ are efficient when $\alpha=$ 0.75 , and only 3 are efficient when $\alpha=1$. The number of efficient DMUs decreases as $\alpha$ increases. Generally, it can be observed that the efficiency value for every DMU decreases (or remains constant) with the increase of $\alpha$. This point was raised in Section 3. The explanation is very straightforward. With a decrease in the spread of value when increasing $\alpha$, the value is confined to a smaller range till it finally becomes one value (mean value) when $\alpha=1$. Thus, by increasing the $\alpha$ value, there is a good chance that the optimum data value gets removed from the range, thereby causing the value to be less optimum and consequently achieving a lower efficiency score. 
TABLE 1: Efficiencies of different DMUs for different $\alpha$ values.

\begin{tabular}{|c|c|c|c|c|c|}
\hline \multirow{2}{*}{ DMU } & \multicolumn{5}{|c|}{$\alpha$} \\
\hline & 0 & 0.25 & 0.50 & 0.75 & 1 \\
\hline$D_{1}$ & 1.0000 & 1.0000 & 1.0000 & 1.0000 & 0.9600 \\
\hline $\mathrm{D}_{2}$ & 1.0000 & 1.0000 & 1.0000 & 1.0000 & 1.0000 \\
\hline$D_{3}$ & 0.4720 & 0.3921 & 0.3261 & 0.2672 & 0.2171 \\
\hline$D_{4}$ & 0.5891 & 0.5062 & 0.4298 & 0.3630 & 0.3027 \\
\hline$D_{5}$ & 0.5666 & 0.4873 & 0.4148 & 0.3482 & 0.2867 \\
\hline$D_{6}$ & 0.6151 & 0.5204 & 0.4371 & 0.3625 & 0.2975 \\
\hline$D_{7}$ & 1.0000 & 1.0000 & 1.0000 & 1.0000 & 0.9400 \\
\hline$D_{8}$ & 0.6899 & 0.6054 & 0.5254 & 0.4494 & 0.3771 \\
\hline$D_{9}$ & 0.2667 & 0.2264 & 0.1874 & 0.1509 & 0.1160 \\
\hline$D_{10}$ & 1.0000 & 1.0000 & 1.0000 & 1.0000 & 1.0000 \\
\hline$D_{11}$ & 0.6220 & 0.5292 & 0.4466 & 0.3748 & 0.3111 \\
\hline$D_{12}$ & 1.0000 & 1.0000 & 1.0000 & 1.0000 & 0.9600 \\
\hline$D_{13}$ & 0.5560 & 0.4772 & 0.4051 & 0.3407 & 0.2800 \\
\hline$D_{14}$ & 1.0000 & 1.0000 & 0.7299 & 0.5257 & 0.3800 \\
\hline$D_{15}$ & 0.4418 & 0.3636 & 0.2980 & 0.2414 & 0.1924 \\
\hline$D_{16}$ & 0.9085 & 0.7425 & 0.5926 & 0.4635 & 0.3520 \\
\hline$D_{17}$ & 0.4117 & 0.3569 & 0.3045 & 0.2543 & 0.2064 \\
\hline$D_{18}$ & 1.0000 & 1.0000 & 1.0000 & 1.0000 & 0.8600 \\
\hline$D_{19}$ & 1.0000 & 1.0000 & 1.0000 & 1.0000 & 1.0000 \\
\hline$D_{20}$ & 1.0000 & 1.0000 & 1.0000 & 0.9672 & 0.7544 \\
\hline
\end{tabular}

For $D_{2}, D_{10}$, and $D_{19}$, their efficiency values remain as 1 . Thus, the efficiency values have not been affected for these DMUs. For $D_{1}, D_{7}, D_{12}, D_{18}$, and $D_{20}$, their efficiency values start at 1 for $\alpha=0$, but by around $\alpha=0.75$ or so, their efficiencies reduce. These DMUs represent the most efficient ones in terms of their RSCs. There are also several DMUs whose efficiencies lie around the 0.5 region. For DMUs whose efficiencies lie below this, their RSCs are highly inefficient. It might be because these DMUs have not considered the environmental, economic, societal, and other aspects of their companies and have therefore performed in an inefficient manner.

Table 2 shows the background information which was also collected from the manufacturers. The average value of efficiency was obtained for the different values of efficiency obtained from different $\alpha$ values. In addition, rankings have been given by sorting the average efficiency scores (see the last column of Table 2). Those DMUs which have low rankings would need a radical change in their RSC in order to become more efficient.

Based on Table 2, some additional insights linking the background information of the companies with the average efficiency scores can be attained. Firstly, it was expected that ISO certification would provide a major edge to the companies in terms of their superior RSC practices, thereby significantly boosting their efficiency scores. Of the 20 companies, 9 of them have an ISO 14001 certification. The average of the efficiencies of the ISO rated companies was 0.7057 . The average of the efficiencies of the others was 0.6107 . Clearly, ISO rated companies have a better efficiency than those not rated. However, if the companies are analyzed individually, then one would notice that ISO certification does not guarantee a company to be efficient in RSC. For example, $D_{3}$ and $D_{4}$ perform below average even though they are ISO certified. This could be because they have utilized more inputs (cost and investment) rather than producing more outputs, to attain the certification. Nevertheless, in average, ISO certification helps to provide a better and more efficient RSC.

The other factor taken into consideration was the duration for which the companies have implemented RSC techniques to improvise their business model. It was thought that the longer the duration, the higher the efficiency score in general. However, apart from a few exceptions, companies with lesser experience have had higher efficiency scores. This was unexpected.

To explain this observation, it could be that the companies which have started implementing RSC techniques recently are bound to have superior technological machinery to perform effective recycling or reusing and therefore have had greater success in achieving more efficient supply chains. It is possible that manufacturers which are old-timers in the field have not managed to update their techniques and machinery or have simply focused on some other aspects of their business model. This might indicate that RSC has lost its momentum in the organizations which have long implementation history and thus they are not performing well. Hence, it seems justifiable that the companies which have recently started utilizing RSC techniques have performed efficiently. 
TABLE 2: Data for background information of each DMU and average efficiency (average of efficiencies obtained from various $\alpha$ values).

\begin{tabular}{|c|c|c|c|c|}
\hline $\mathrm{DMU}$ & Average efficiency & ISO certification & Years since RSC was implemented & Efficiency ranking \\
\hline$D_{1}$ & 0.9920 & No & 2 & 4 \\
\hline$D_{2}$ & 1.0000 & No & 4 & 1 \\
\hline$D_{3}$ & 0.3349 & Yes & 3 & 17 \\
\hline$D_{4}$ & 0.4382 & Yes & 6 & 14 \\
\hline$D_{5}$ & 0.4207 & No & 10 & 15 \\
\hline$D_{6}$ & 0.4465 & No & 4 & 13 \\
\hline$D_{7}$ & 0.9880 & Yes & 12 & 6 \\
\hline$D_{8}$ & 0.5294 & Yes & 5 & 11 \\
\hline$D_{9}$ & 0.1895 & No & 9 & 20 \\
\hline$D_{10}$ & 1.0000 & Yes & 2 & 1 \\
\hline$D_{11}$ & 0.4567 & Yes & 6 & 12 \\
\hline$D_{12}$ & 0.9920 & Yes & 13 & 4 \\
\hline$D_{13}$ & 0.4118 & No & 5 & 16 \\
\hline$D_{14}$ & 0.7271 & No & 2 & 9 \\
\hline$D_{15}$ & 0.3074 & No & 9 & 18 \\
\hline$D_{16}$ & 0.6118 & Yes & 4 & 10 \\
\hline$D_{17}$ & 0.3068 & No & 5 & 19 \\
\hline$D_{18}$ & 0.9720 & No & 3 & 7 \\
\hline$D_{19}$ & 1.0000 & Yes & 3 & 1 \\
\hline$D_{20}$ & 0.9443 & No & 8 & 8 \\
\hline
\end{tabular}

It is worth noting that in terms of other background information of the companies (i.e., type of industry and number of employees), no particular insight could be inferred between these factors and the average efficiency scores.

In terms of managerial implications, the model is applicable to evaluate RSC performance from a manufacturer's perspective. For each DMU and for every $\alpha$ value, the model is able to consolidate multiple input and output measures into one efficiency score. The model does not need precise data and it serves as a useful benchmarking tool to evaluate the RSC performances of various organizations. The results could help the DMUs under evaluation to have an overview on how well their RSC is performing in relation to others. Consequently, they could strategize and take appropriate actions to improve their RSC efficiency which will enable them to be more sustainable environmentally, economically, and socially.

\section{Conclusions}

Supply chain management is one of the most discussed topics in the commercial literature. Measuring the efficiency of a supply chain is a heavily researched topic. Despite this, there are very few papers which have attempted to measure RSC efficiency. This area remains to be one of the least developed areas in supply chain studies. In this paper, DEA has been used to measure RSC performance from a manufacturer's perspective. Since precise data would have been difficult to obtain, a fuzzy version of the CCR model was used to solve the problem. It was converted into a parametric programming model with $\alpha$ being the parameter. A questionnaire survey was conducted and data from 20 companies were collected.
The data were then analyzed using the fuzzy CCR model and the efficiency scores for various $\alpha$ values were obtained. It was observed that the efficiency scores reduce with increasing $\alpha$ values. This was expected as with increasing $\alpha$ values, the range of inputs reduces, thereby reducing the chance that the optimized input is chosen. In addition, the efficiency scores were used to allot efficiency ranks.

The paper then compared the organizational background information with the rankings to get some additional insights. It was observed that in average, the companies certified with ISO 14001 performed slightly better than those without the certification. This was expected as ISO certification ensures a lesser impact on the environment, which is one of the performance attributes of the model. In addition, it was found that, in general, companies with lesser years of RSC implementation could perform better than those which have implemented it for a longer period.

The model is applicable to evaluate RSC performance from a manufacturer's perspective. By providing different efficiency scores for each $\alpha$ value, managers can have an overview on their RSC performance and have flexibility to judge the results based on their experience. The next stage of this research will be extending the evaluation to other parties in the entire RSC. It would be more challenging as the number of input and output measures will be higher, and thus the amount of data to be collected will be greater and the programming will be more complicated. Another avenue for future research is to use the model in a longitudinal study to measure RSC performance before and after certain initiatives or interventions. Lastly, researchers can work on the model to measure the performance of a complete closed-loop supply chain that includes both the forward and reverse chains. 


\section{Appendix}

Questionnaire

Part A: Background Information

(1) Type of industry (with reference to product):

(2) Number of employees in your company:

(3) How long has your company implemented reverse supply chain activities such as collecting end-oflife products, recycling and reprocessing them? Years

(4) What certification or award has your company received in reverse supply chain management (such as ISO 14001 certification)?

Part B: Reverse Supply Chain Performance Evaluation Measures

(1) How much operational and technological cost is involved in your company's reverse supply chain activities (such as recycling and reprocessing)?

$$
\begin{aligned}
& \square \text { Very High } \\
& \square \text { High } \\
& \square \text { Normal } \\
& \square \text { Low } \\
& \square \text { Very Low }
\end{aligned}
$$

(2) How much financial investment is involved in your company's environmental initiatives (such as awareness campaign, advertisement and certification)?

$$
\begin{aligned}
& \square \text { Very High } \\
& \square \text { High } \\
& \square \text { Normal } \\
& \square \text { Low } \\
& \square \text { Very Low }
\end{aligned}
$$

(3) How is the relationship between your company and other parties that are involved in the reverse supply chain?

$$
\begin{aligned}
& \square \text { Very Strong } \\
& \square \text { Strong } \\
& \square \text { Normal } \\
& \square \text { Weak } \\
& \square \text { Very Weak }
\end{aligned}
$$

(4) How much have the reverse supply chain activities helped the environment (in terms of reducing pollution, carbon footprint and energy consumption)?

$$
\begin{aligned}
& \square \text { Very Significant } \\
& \square \text { Significant } \\
& \square \text { Average }
\end{aligned}
$$

\author{
$\square$ Insignificant \\ $\square$ Very Insignificant
}

(5) How much have the reverse supply chain activities helped the economy (in terms of cost saving and profit generation)?

$$
\begin{aligned}
& \square \text { Very Significant } \\
& \square \text { Significant } \\
& \square \text { Average } \\
& \square \text { Insignificant } \\
& \square \text { Very Insignificant }
\end{aligned}
$$

(6) How much have the reverse supply chain activities contributed to the society (in terms of improving quality of life, health and wellness)?

$$
\begin{aligned}
& \square \text { Very Significant } \\
& \square \text { Significant } \\
& \square \text { Average } \\
& \square \text { Insignificant } \\
& \square \text { Very Insignificant }
\end{aligned}
$$

\section{Conflict of Interests}

The authors declare that there is no conflict of interests regarding the publication of this paper.

\section{References}

[1] K. Govindan and M. N. Popiuc, "Reverse supply chain coordination by revenue sharing contract: a case for the personal computers industry," European Journal of Operational Research, vol. 233, no. 2, pp. 326-336, 2014.

[2] K. Govindan, J. Sarkis, C. J. C. Jabbour, Q. Zhu, and Y. Geng, "Eco-efficiency based green supply chain management: current status and opportunities," European Journal of Operational Research, vol. 233, no. 2, pp. 293-298, 2014.

[3] A. Charnes, W. W. Cooper, and E. Rhodes, "Measuring the efficiency of decision making units," European Journal of Operational Research, vol. 2, no. 6, pp. 429-444, 1978.

[4] C. Prahinski and C. Kocabasoglu, "Empirical research opportunities in reverse supply chains," Omega, vol. 34 , no. 6, pp. 519$532,2006$.

[5] B. Trebilcock, "The seven deadly sins of reverse logistics," Logistics Management and Distribution, vol. 41, no. 6, pp. 31-34, 2002.

[6] R. Farel, B. Yannou, A. Ghaffari, and Y. Leroy, "A cost and benefit analysis of future end-of-life vehicle glazing recycling in France: a systematic approach," Resources, Conservation and Recycling, vol. 74, pp. 54-65, 2013.

[7] V. D. R. Guide Jr., T. P. Harrison, and L. N. van Wassenhove, "The challenge of closed-loop supply chains," Interfaces, vol. 33, no. 6, pp. 3-6, 2003.

[8] M. S. Pishvaee and J. Razmi, "Environmental supply chain network design using multi-objective fuzzy mathematical programming," Applied Mathematical Modelling, vol. 36, no. 8, pp. 3433-3446, 2012. 
[9] P. Taticchi, F. Tonelli, and R. Pasqualino, "Performance measurement of sustainable supply chains: a literature review and a research agenda," International Journal of Productivity and Performance Management, vol. 62, no. 8, pp. 782-804, 2013.

[10] R. Handfield, S. V. Walton, R. Sroufe, and S. A. Melnyk, "Applying environmental criteria to supplier assessment: a study in the application of the Analytical Hierarchy Process," European Journal of Operational Research, vol. 141, no. 1, pp. 7087, 2002.

[11] J. Sarkis, "A strategic decision framework for green supply chain management," Journal of Cleaner Production, vol. 11, no. 4, pp. 397-409, 2003.

[12] R. Pineda-Henson, A. B. Culaba, and G. A. Mendoza, "Evaluating environmental performance of pulp and paper manufacturing using the analytic hierarchy process and life-cycle assessment," Journal of Industrial Ecology, vol. 6, no. 1, pp. 1528, 2002.

[13] W.-H. Tsai and S.-J. Hung, "A fuzzy goal programming approach for green supply chain optimisation under activity-based costing and performance evaluation with a value-chain structure," International Journal of Production Research, vol. 47, no. 18, pp. 4991-5017, 2009.

[14] V. Ravi, R. Shankar, and M. K. Tiwari, "Analyzing alternatives in reverse logistics for end-of-life computers: ANP and balanced scorecard approach," Computers and Industrial Engineering, vol. 48, no. 2, pp. 327-356, 2005.

[15] E. U. Olugu and K. Y. Wong, "Fuzzy logic evaluation of reverse logistics performance in the automotive industry," Scientific Research and Essays, vol. 6, no. 7, pp. 1639-1649, 2011.

[16] J. K. Sengupta, "A fuzzy systems approach in data envelopment analysis," Computers and Mathematics with Applications, vol. 24, no. 8-9, pp. 259-266, 1992.

[17] S.-J. Chen and C.-L. Hwang, Fuzzy Multiple Attribute Decision Making: Methods and Applications, vol. 375 of Lecture Notes in Economics and Mathematical Systems, Springer, Berlin, Germany, 1992.

[18] S. Lertworasirikul, S. C. Fang, J. A. Joines, and H. L. W. Nuttle, "A possibility approach to fuzzy data envelopment analysis," in Proceedings of the 6th Joint Conference on Information Sciences (JCIS '02), pp. 176-179, Triangle Park, NC, USA, March 2002.

[19] S. Lertworasirikul, S. C. Fang, H. L. W. Nuttle, and J. A. Joines, "Fuzzy data envelopment analysis," in Proceedings of the 9th Bellman Continuum, pp. 342-353, Beijing, China, 2002.

[20] S. Lertworasirikul, S. C. Fang, J. A. Joines, and H. L. W. Nuttle, "Fuzzy data envelopment analysis (DEA): a possibility approach," Fuzzy Sets and Systems, vol. 139, no. 2, pp. 379-394, 2003.

[21] E. E. Karsak, "Using data envelopment analysis for evaluating flexible manufacturing systems in the presence of imprecise data," International Journal of Advanced Manufacturing Technology, vol. 35, no. 9-10, pp. 867-874, 2008.

[22] S. M. Saati, A. Memariani, and G. R. Jahanshahloo, "Efficiency analysis and ranking of DMUs with fuzzy data," Fuzzy Optimization and Decision Making, vol. 1, no. 3, pp. 255-267, 2002.

[23] T. Hacking and P. Guthrie, "A framework for clarifying the meaning of triple bottom-line, integrated, and sustainability assessment," Environmental Impact Assessment Review, vol. 28, no. 2-3, pp. 73-89, 2008.

[24] J. D. Blackburn, V. D. R. Guide Jr., G. C. Souza, and L. N. van Wassenhove, "Reverse supply chains for commercial returns," California Management Review, vol. 46, no. 2, pp. 6-22, 2004.
[25] M. K. Chien and L. H. Shih, "An empirical study of the implementation of green supply chain management practices in the electrical and electronic industry and their relation to organizational performances," International Journal of Environmental Science and Technology, vol. 4, no. 3, pp. 383-394, 2007.

[26] A. M. Papadopoulos and E. Giama, "Environmental performance evaluation of thermal insulation materials and its impact on the building," Building and Environment, vol. 42, no. 5, pp. 2178-2187, 2007.

[27] Q. Zhu and J. Sarkis, "Relationships between operational practices and performance among early adopters of green supply chain management practices in Chinese manufacturing enterprises," Journal of Operations Management, vol. 22, no. 3, pp. 265-289, 2004.

[28] Y. K. P. Wan and S. H. J. Chan, "Casino employees' perceptions of their quality of work life," International Journal of Hospitality Management, vol. 34, no. 1, pp. 348-358, 2013.

[29] B. Golany and Y. Roll, "An application procedure for DEA," Omega, vol. 17, no. 3, pp. 237-250, 1989.

[30] W. F. Bowlin, "Measuring performance: an introduction to Data Envelopment Analysis (DEA)," Journal of Cost Analysis, vol. 15, no. 2, pp. 3-27, 1998.

[31] R. G. Dyson, R. Allen, A. S. Camanho, V. V. Podinovski, C. S. Sarrico, and E. A. Shale, "Pitfalls and protocols in DEA," European Journal of Operational Research, vol. 132, no. 2, pp. 245-259, 2001. 


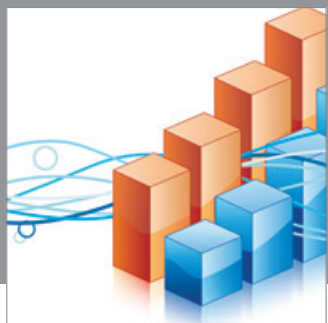

Advances in

Operations Research

mansans

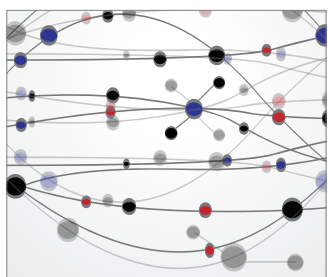

The Scientific World Journal
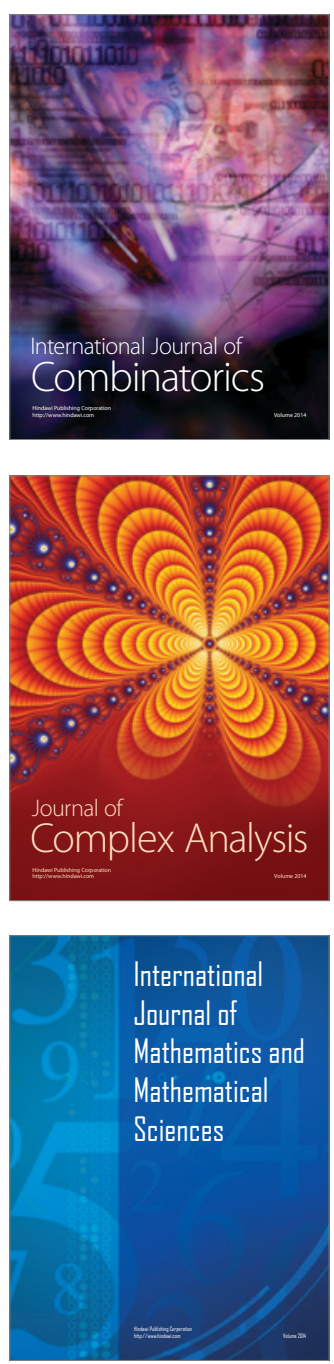
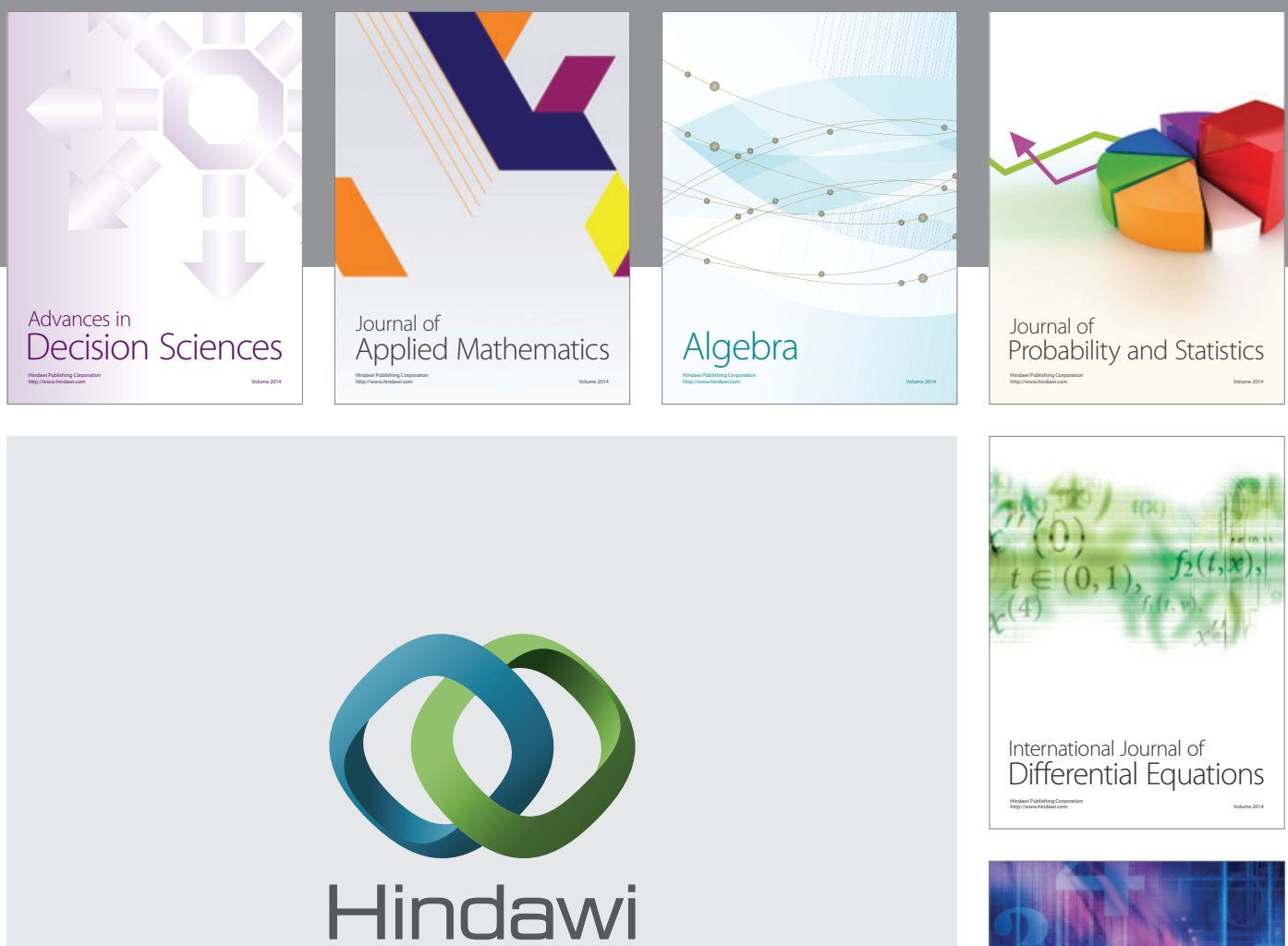

Submit your manuscripts at http://www.hindawi.com
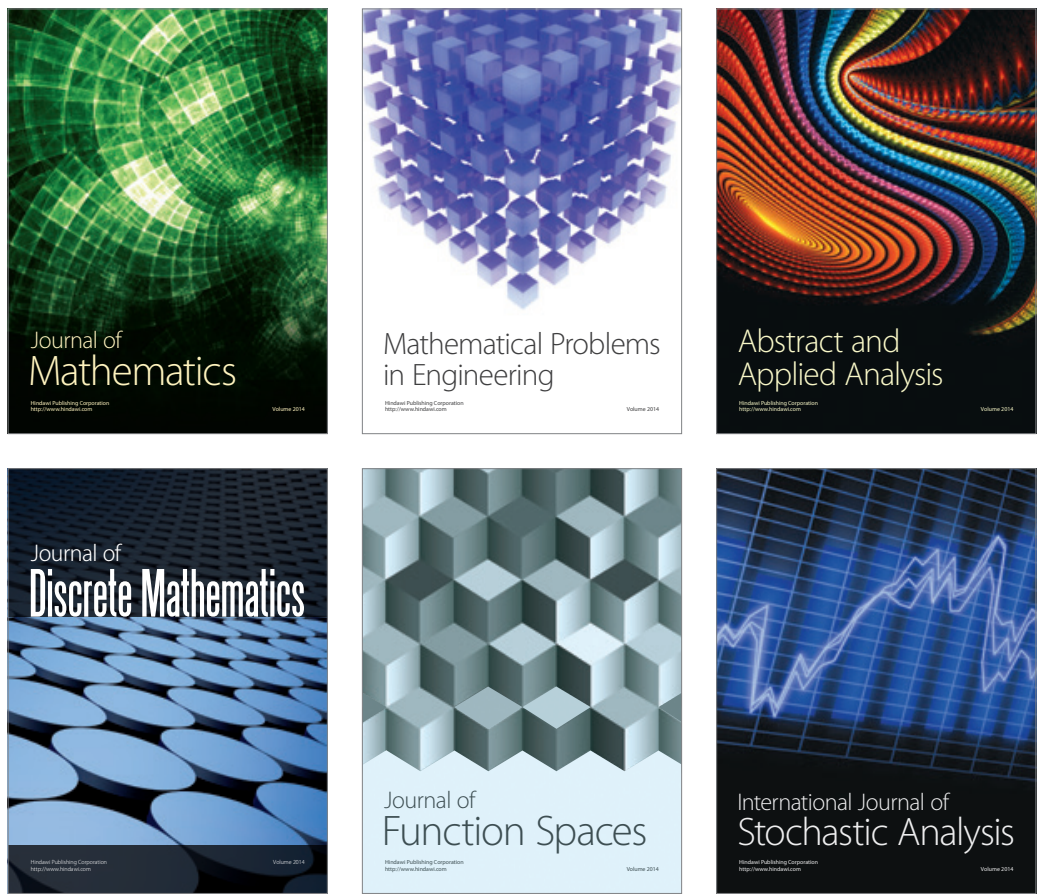

Journal of

Function Spaces

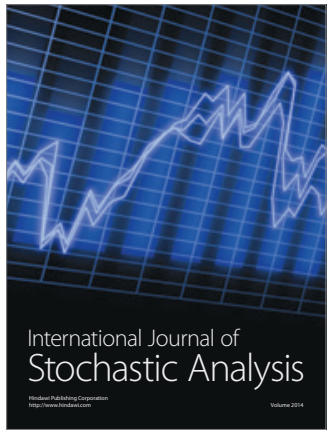

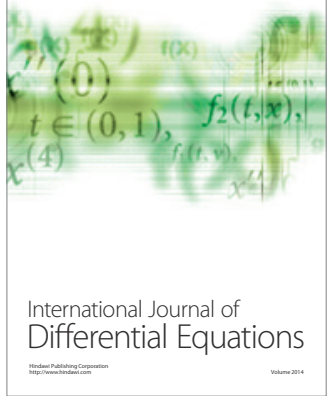
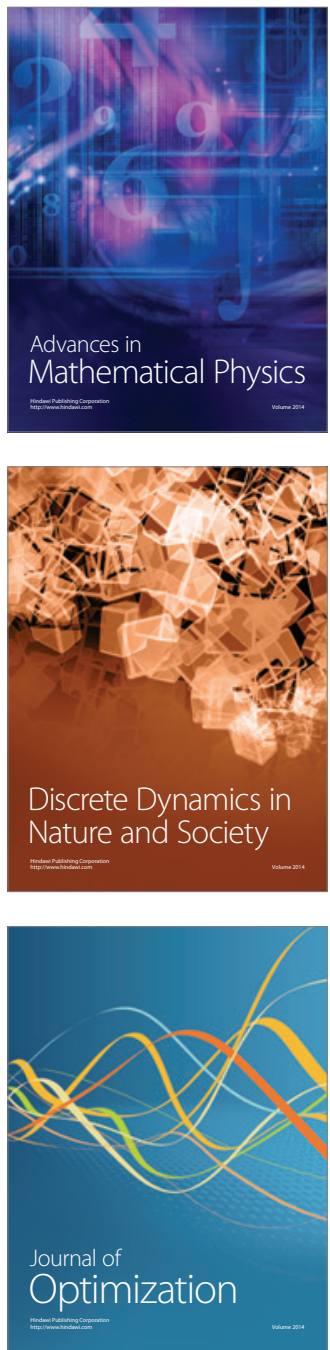